\title{
Eosinophilic cholecystitis as a rare manifestation of visceral larva migrans
}

\author{
Hitoshi Yoshiji, Masahide Yoshikawa, Kosuke Kaji, Hiroshi Fukui
}

Hitoshi Yoshiji, Kosuke Kaji, Hiroshi Fukui, Third Department of Internal Medicine, Nara Medical University, Nara, Japan

Masahide Yoshikawa, Department of Parasitology, Nara Medical

University, Nara, Japan

Correspondence to: Hitoshi Yoshiji, Third Department of Internal Medicine, Nara Medical University, Nara,

Japan.yoshijih@naramed-u.ac.jp

Telephone: +81-744-223051 Fax: +81-744-247122

Received: August 10,2007 Revised: September 3, 2007

\begin{abstract}
Eosinophilic cholecystitis is an infrequent form of cholecystitis. The etiology of eosinophilic cholecystitis is still obscure, and it is sometimes accompanied with several complications, but a simultaneous onset with pericarditis is very rare. We would like to make an alternative interpretation of our recent report "Kaji $\mathrm{K}$, Yoshiji H, Yoshikawa M, Yamazaki M, Ikenaka Y, Noguchi R, Sawai M, Ishikawa M, Mashitani T, Kitade M, Kawaratani H, Uemura M, Yamao J, Fujimoto M, Mitoro A, Toyohara M, Yoshida M, Fukui H. Eosinophilic cholecystitis along with pericarditis caused by Ascaris lumbricoides: A case report. World J Gastroenterol 2007; 13: 3760-3762."
\end{abstract}

(c) 2007 WJG. All rights reserved.

Key words: Cholecystitis; Visceral larva migrans; Parasite; Ascaris suum; Toxocara canis

Yoshiji H, Yoshikawa M, Kaji K, Fukui H. Eosinophilic cholecystitis as a rare manifestation of visceral larva migrans. World J Gastroenterol 2007; 13(45): 6119

http://www.wjgnet.com/1007-9327/13/6119.asp

\section{TO THE EDITOR}

Eosinophilic cholecystitis is an infrequent form of cholecystitis. The etiology of eosinophilic cholecystitis is still obscure, and it is sometimes accompanied by several complications, but a simultaneous onset with pericarditis is very $\operatorname{rare}^{[1-3]}$.
We would like to make an alternative interpretation of our recent report "Kaji K, Yoshiji H, Yoshikawa M, Yamazaki M, Ikenaka Y, Noguchi R, Sawai M, Ishikawa M, Mashitani T, Kitade M, Kawaratani H, Uemura M, Yamao J, Fujimoto M, Mitoro A, Toyohara M, Yoshida M, Fukui H. Eosinophilic cholecystitis along with pericarditis caused by Ascaris lumbricoides: A case report. World J Gastroenterol 2007; 13: 3760-3762." We reported that this rare clinical manifestation was caused by Ascaris lumbricoides. However, from the serological diagnosis, it was likely that these clinical symptoms were visceral larva migrans (VLM) caused by Ascaris suum or Toxocara canis rather than by Ascaris lumbricoides. While a definitive diagnosis of parasitic diseases is established after the detection of worms or eggs from the patient, the direct detection of the worm is quite rare. As we described in the report, we could not make a direct detection of the worm either. Generally, foodborne parasitic infection can be diagnosed based on the raw food intake history, laboratory data such as hypereosinophila, and the presence of antibody against the parasite in the serum. Our patient revealed a higher titer of antibody against Ascaris suum and Toxocara canis by enzyme-linked immunosorbant assay by 150 and 100 fold as compared with the control serum. Nevertheless, we can not rule out the possibility that it is caused by Ascaris lumbricoides. Ascaris lumbricoides also could penetrate the gastrointestinal tract.

In conclusion, since the title was too high in our study, we had to consider other alternative possibilities of VLM caused by Ascaris sum or Toxocara canis as described above, and we believe that this letter would help make our previous report more easily understood and legible for the readers.

\section{REFERENCES}

1 Matsuki Y, Fujii T, Nakamura-Uchiyama F, Hiromatsu K, Nawa Y, Hayashi T, Ohtomi S. Toxocariasis presenting with multiple effusions in the pericardial space, thoracic cavity, and Morrison's pouch. Intern Med 2007; 46: 913-914

2 Mir-Madjlessi SH, Sivak MV Jr, Farmer RG. Hypereosinophilia, ulcerative colitis, sclerosing cholangitis, and bile duct carcinoma. Am J Gastroenterol 1986; 81: 483-485

3 Schoonbroodt D, Horsmans Y, Laka A, Geubel AP, Hoang $\mathrm{P}$. Eosinophilic gastroenteritis presenting with colitis and cholangitis. Dig Dis Sci 1995; 40: 308-314

S- Editor Liu Y L- Editor Ma JY E- Editor Li HY 